POLLACK PERIODICA

An International Journal for Engineering and Information Sciences

DOI: $10.1556 / 606.2020 .15 .3 .22$

Vol. 15, No. 3, pp. 232-242 (2020)

www.akademiai.com

\title{
RESTORING RURAL LANDSCAPE: A CASE STUDY IN CHONGQING CHINA
}

\author{
${ }^{1}$ Yongting SHI ${ }^{*}{ }^{2}$ Anna Mária TAMÁs, ${ }^{3}$ Gergely SZTRANYÁK \\ ${ }^{1}$ Marcel Breuer Doctoral School, Faculty of Engineering and Information Technology \\ University of Pécs, Boszorkány u. 2, H-7624 Pécs, Hungary; Faculty of Fine Arts, Chongqing \\ Normal University, Chongqing, China, e-mail: shiyongting@foxmail.com \\ ${ }^{2}$ Department of Architecture and Urban Planning, Faculty of Engineering and Information \\ Technology, University of Pécs, Boszorkány u. 2, H-7624 Pécs, Hungary \\ e-mail: anima@mik.pte.hu \\ ${ }^{3}$ Department of Building Structure and Energy Design, Faculty of Engineering and \\ Information Technology, University of Pécs, Boszorkány u. 2, H-7624 Pécs, Hungary \\ e-mail: sztranyak.gergely@mik.pte.hu
}

Received 26 December 2019; accepted 21 March 2020

\begin{abstract}
Based on the consensus that the rural cultural landscape with regional characteristics is conducive to promoting the sustainable development of rural areas, this study explores how to use multiple means to restore the countryside with insufficient or severely damaged landscape resources and rebuild the contemporary rural landscape with regional characteristics. Combining the design of practical cases, the article proposes the use of low-tech, low-interference vernacular technology, and the integration of artistic intervention methods can more effectively restore landscape characteristics and stimulate rural development vitality.
\end{abstract}

Keywords: Rural landscape, Regional characteristics, Low-tech, Artistic intervention

\section{Introduction}

Rural landscapes are terrestrial and aquatic areas co-produced by human-nature interaction used for the production of food and other renewable natural resources. Rural landscapes are multifunctional resources [1]. It carries the development of culture, records the history of mankind, is the main material carrier of national characteristics and regionalism, and is the important supporting element of sustainable rural development. China is a country developed from a rural society. With rapid urbanization, the rural areas and population still occupy an important ratio in the country. However, due to imbalanced development, hollowing out of the village, and

\footnotetext{
${ }^{*}$ Corresponding Author
} 
aging of the population, this vast land that gave birth to culture has caused rural poverty and loss of characteristics, making development difficult.

The current situation and future development of rural areas have become the focus of the world. The International Council on Monuments and Sites (ICOMOS) has identified the theme of the international day 2019 as 'Rural landscape'. This event highlights the value of conserving this heritage formed through long-term, harmonious interaction between humankind and the natural environment aiming to explore the path of sustainable rural development through collaborative research.

The predicament of China's rural development has caused the government to attach great importance to it and has implemented a series of policies to promote rural revitalization. In the past 20 years, a large number of researchers, professional institutions, management methods, policies and funds have been involved into the countryside, and they have jointly explored the path of sustainable rural development from multiple perspectives and dimensions. This design project was born in this context.

\subsection{Project overview}

Zhongyi Township, Shizhu County, Chongqing is located in the northeast of Shizhu County. It is a part of the forest in the Wuling Mountains, located in the valley zone. The countryside is 21 kilometers long from east to west, 7.5 kilometers wide from north to south, 55 kilometers away from the county center, covering an area of 155 square kilometers. Within the territory of mountains overlap, ravines, moderate climate, abundant rainfall, forest coverage rate of $85.3 \%$.

The total population of the township is 8,232 , most of whom are members of the Tujia minority. Because of its remote location and barren land, the incidence of poverty in the whole township is as high as $7.6 \%$, which is one of the 18 deeply impoverished townships in Chongqing.

In order to get rid of poverty and become rich, Zhongyi Township adopted a series of methods to adjust the industrial structure. Under the guidance and organization of the government, various crops suitable for the local climate and soil were introduced to increase farmers' income. At the same time, in combination with the characteristics of climate and vegetation, the bee breeding industry has been vigorously developed, and not only breeding bases have been established, but also honey processing plants have been established. Therefore, honey has become a new and distinctive product in this region, which not only generates income for local farmers, but also lays a foundation for the development of distinctive recreational tourism. Therefore, Zhongyi Township aims to develop rural health tourism with regional characteristics and integrated industrial development.

\subsection{Design tasks}

The rural landscape with distinctive features is conducive to promoting the development of rural tourism and the sustainable development of the countryside. This view has become an international consensus. As a survey indicated that the reconstruction had significant contribution to economic situation in the places of 
reconstruction. Greatest contribution in this sense is realized through increased tourism, (i.e. through increased visiting, and through increased employment) [2]. Therefore, this project was entrusted by the local government. After understanding the local industrial development goals, combining the site characteristics and actual conditions of the site, combining with the development goals of the area, based on field surveys, the pilot areas are selected to build regional rural features Landscape. Promote the development of rural tourism by shaping the rural cultural landscape with regional characteristics.

\section{Design methodology}

Fieldwork is the first step in this project. In the base investigation, the spatial pattern of Zhongyi Township, the relationship between mountain and forest fields and residential areas, the distribution of roads, the relationship between rivers and villages, the aesthetics of spatial forms, and the basic situation of buildings have become important objects of investigation. Drones, photo recordings, sketches and depictions are fully used in the process.

After having an intuitive impression of the village, the next task is to visit the local residents and get to know the villagers' desire for the development of the village through multiple concentrated exchanges, especially in-depth exchanges with the villagers who are willing to provide inn services, to understand the current situation of their houses, the difficulties in providing inn services. Following this work the design team proposed three pilot area options and identified them in consultation with government staff and village representatives.

After comparison, analysis and discussion, the design team and stakeholders reached a consensus and confirmed the two places as design objects. The design team conducted in-depth research on these two sites to analyze and summarize the existing problems of the site. In view of the existing problems, the design team invited representatives from all sides to discuss and propose preliminary design strategies.

\subsection{Site analysis}

The two pilot sites are located on the inevitable road between Shizhu County and Zhongyi Township. One, named Longjiaba, is located in the border area of Zhongyi Township, making it a visual display. Good rural landscape will attract people to explore and stay. Another area, called Guankouyan, is close to the core area and has a relatively open roadside zone, which can be used as a tourist reception area. The residential houses in the two pilot areas are distributed along the side of the highway in a linear pattern, following the direction of the mountains from the northwest to the southeast, quietly rooted in the foothill valley on the other side of the road is the Long River, which runs down the valley. The river width varies with the terrain, the water is clear, and there are rocky beaches in the river. The entire base presents a gradual undulating space pattern composed of rivers, roads, houses and mountain and forest fields. The houses built according to the terrain are intertwined with old and new, with high and low levels, which is quite idyllic. 
The Longjiaba area of the courtyard is $17,000 \mathrm{~m}^{2}$, with about 18 households. There are 38 new brick houses, rammed earth old houses, wooden structure old houses, and 16 separate toilets. The Guankouyan area of the courtyard is $12,500 \mathrm{~m}^{2}$, with about 25 households. There are 39 new brick houses, rammed earth old houses and wooden structure old houses, and 7 enclosed houses and independent toilets.

\subsection{Problem statement}

The pilot site has a good overall ecological environment and spatial structure, abundant vegetation, and is located in an important geographical location aiming at tourism development. However, there are serious practical problems in the region that need to be changed. Based on the analysis of the current situation of the site and the design goals, the following problems in the local rural landscape can be summarized:

A. Buildings as the main living space in the rural landscape: Due to the long-term poverty, the local old buildings with regional characteristics are in disrepair and have hidden safety problems. In order to change their living conditions, some farmers with better economic conditions tore down the old houses and built new houses. However, the new houses were poorly built, not only without local characteristics, but the exposed plastered wall and rough brick wall without aesthetic feeling even became the 'scar' that destroyed the harmonious sense of pastoral landscape (as it is shown in Fig. 1);

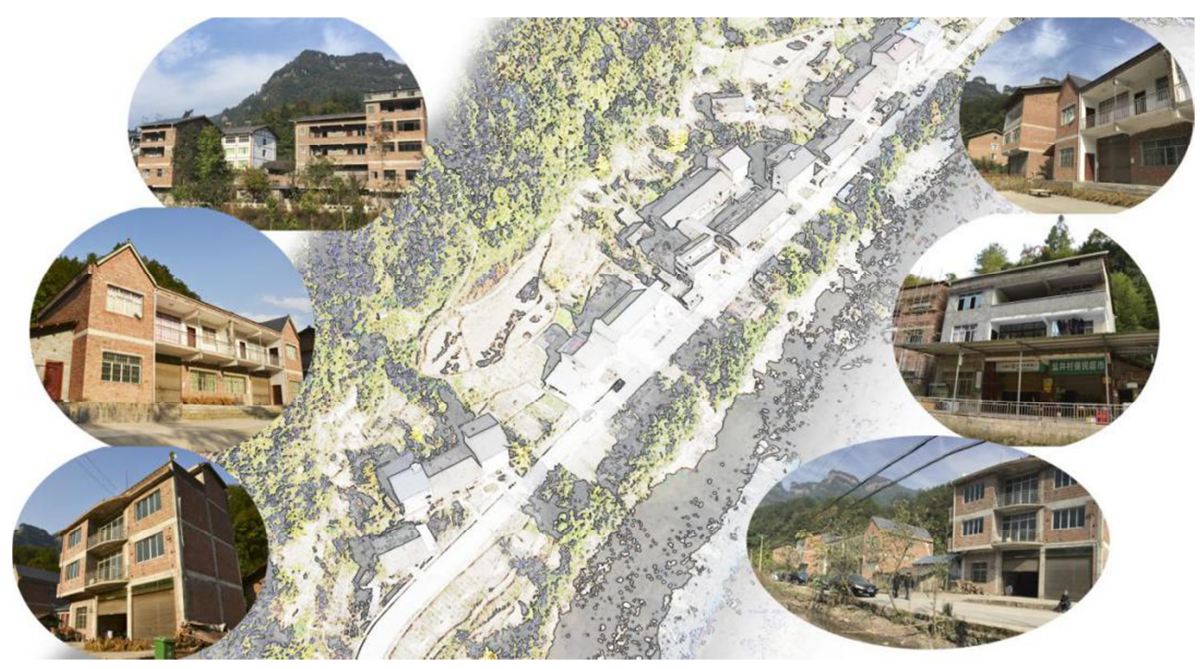

Fig. 1. Construction status of the pilot site (Source: photo and designed by Y. Shi)

B. As an important place for human living activities in the rural landscape courtyard: as an outdoor extension of people's living space, courtyard is a transitional space between living and production activities and is also a multifunctional space. The courtyards of the pilot areas are unordered to pile up more sundries, sewage and garbage can be seen everywhere. Not only visual 
aesthetic feeling is poor, life quality feeling is low and the space use function is weak;

C. As an important place for human production activities in the rural landscape fields: There is a weak correlation between crop varieties in the surrounding farming areas and the Chinese bee breeding industry. Bare land is often seen, and vegetation lacks seasonal variability, which cannot effectively support the development of rural tourism;

D. As an important natural element in the rural landscape - river: the water is clear, but there is much garbage along the river bank. The area between Long River and the highway is mostly wasteland, with low vegetation coverage, which has not been used effectively. The site lacks suitable hydrophilic space and public space.

In summary, the rural landscape elements in the pilot areas have a good spatial pattern and basic conditions, but the lag and disordered development in recent decades not only weakened the local regional traditional characteristics, but also damaged the ecological environment to a certain extent, which is in urgent need of repair.

\subsection{Design strategy}

The design team proposed to restore the rural landscape of the pilot areas with the theme of 'pastoral environment, health and honey countryside'. In combination with the industrial characteristics and tourism development needs of Zhongyi township, the development goal is to cultivate the honey township, the design object is the idyllic environment, and the low-tech strategies and artistic intervention are the implementation means to restore the rural landscape, the scene of mountains and fields and the people's happy living.

Researchers view low technology as the opposite of high technology. Low technology, often abbreviated low-tech, is simple technology, often of a traditional or non-mechanical kind. Low tech can commonly be created with the least capital investment by the individuals or small groups. It increases dependence on the local natural resources and passive strategies to provide a stable comfortable environment, while using simple construction methods [3]. Also, the knowledge of the practice can be completely comprehended by a single individual, free from increasing specialization and compartmentalization. The construction concept of low technology, which is harmonious with nature and attaches importance to handwork techniques, is fully embodied in local architecture. Even in today's society, low-tech is still very much in play in remote and non-large-scale construction projects.

Artistic intervention is an interaction with a previously existing artwork, audience, space or situation. The concept of artistic intervention lacks consistency in the academic domain and is associated with various umbrella terms; it contains work arts, art-based initiatives, artful learning alliances, and art-based interventions [4]. Artistic intervention refers to the effect of introducing art into a work setting, thereby affecting the culturally engrained routines and perspectives of an organization. New relationships are established to transform organizations [5]. Intervention can also refer to art, which enters a situation outside the art world in an attempt to change the existing conditions 
there. For example, intervention art may attempt to change economic or political situations or may attempt to make people aware of a condition that they previously had no knowledge of. At present in China, art is actively involved in rural construction by various forms with a vigorous momentum. The art intervention adopted in this study is that the village presents a feature of life aesthetics, ecological beauty, production and cultural creation through the participation of artists, related organizations and villagers in art creation and artistic activities.

\section{Final design}

\subsection{Use art intervention to enhance the experience of rural landscape}

The construction of rural tourism characteristics is usually based on the experience of the experiencer. For the experiencer, the sensory impression of the initial contact will occupy an important part of the intuitive feeling. The impression may be a fragrant aroma, a delightful visual image, or a beautiful moving melody. The design team was thinking about how to build this first impression from the beginning of the design. The involvement of public art is not only the ornaments and works of art, and it also considers and treats the public environment from the perspective of art, so as to optimize the living conditions and its own situation [6]. On the way to the pilot area, visitors will pass the bottom of a viaduct. The viaduct is the physical evidence that the artificial construction fully demonstrates human power in the natural environment. However, the relationship between the shape of the bridge and the treatment of the bridge piers and nature is rather rigid, which has become the disadvantage in the ecological landscape. The design team tries to use design to turn weaknesses into strengths. After a series of brainstorming, they finally reached the goal of enhancing the recognition of the site by displaying the landscape art that highlights the tourism characteristics of the area. The design uses the volume of columns and uses a combination of $3 \mathrm{D}$ painting and $3 \mathrm{D}$ installation to create a group of masterpieces that combine flowers, honey and field scenery to form a stunning visual effect. Use the superb artistic expression to create a surprise visual first experience for the pilot area as it is shown in Fig. 2.

\subsection{Reconstruct buildings and strengthen the regional characteristics with low-tech}

As it has been stated in the previous analysis, the existing building facades in the pilot areas are ugly, lacking features and aesthetics. The building facade in this project, as a large proportion of the rural landscape, is an important part of the tourist experience, so it needs to be adjusted urgently. In view of the project's limited budget, overall engineering volume, and remote location, low-tech strategies are used to transform it. The design team made an in-depth analysis of the regional characteristics of the local buildings by investigating the existing old buildings, and then proposed low-tech transformation methods. This method is based on the construction materials, types and years of the buildings to be modified to give different and appropriate lowtech renovation. First of all, the exterior facade of the existing buildings was 
characterized to meet the basic aesthetic requirements of rural tourism development. After achieving this goal, the functions of some buildings were transformed according to the wishes of villagers to meet the needs of tourism services.

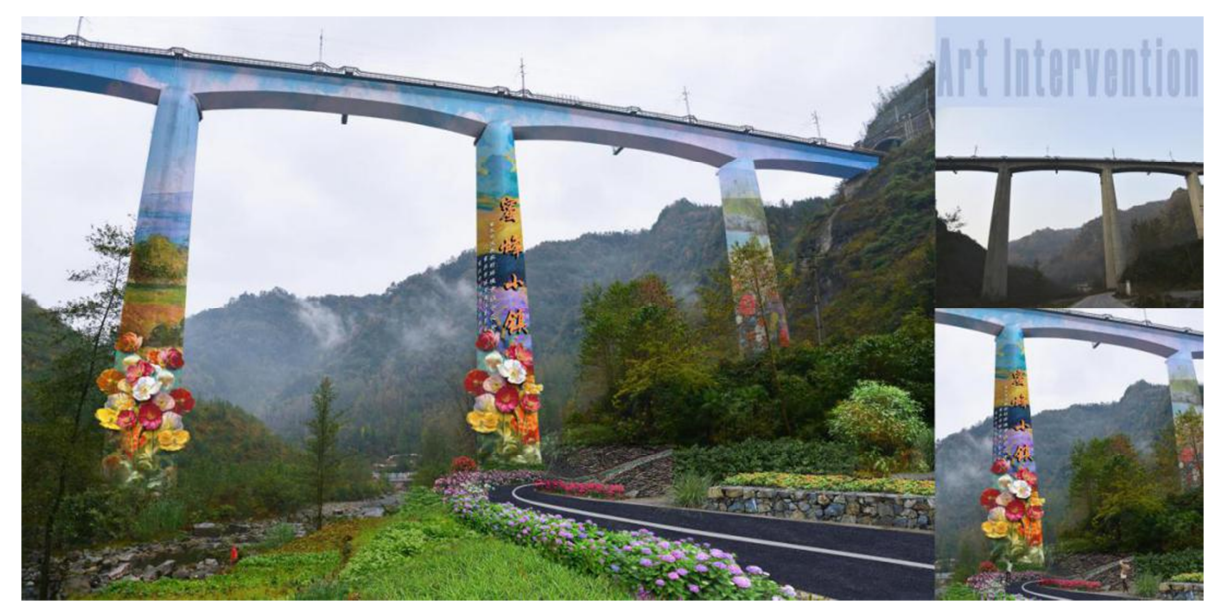

Fig. 2. Viaduct columns designed with artistic techniques

(Source: designed and drawn by Y. Shi and Y. Zhao)

For the common buildings with exposed and non-characteristic exterior walls, the design combines the features of function and form, and improves the surface wall by coating the weather-resistant earthen yellow exterior wall paint. Combined with the characteristics of traditional Tujia dwellings, the local architectural components with Tujia architectural features, either traditional or modern, are added organically to the facades. It uses the appearance full of morphological changes and rhythms to highlight the local culture and restore the original rural style and characteristics as it is shown in Fig. 3. After the restoration of the building's facade, it is designed to decorate the building's exterior walls with life, industry and themes. For example, a wooden frame is built on the building's gable wall to facilitate plant climbing, so that the plant is threedimensional. Add a structure that can hold beehives to strengthen the theme of the area. These transformation methods are designed based on traditional building components and craftsmanship and can be completed by local manual builders.

The past never returns. Nevertheless, significant references from the past could be rediscovered in the field of architecture design. History is a process of dynamic development. Vernacular architecture of different periods and regions always represents and adapts to human demands and lifestyle [7]. The structure of old buildings has begun to deform, but the vicissitudes of appearance over time have been very precious and need protection. The design recommends strengthening the structure from the inside to the outside, replacing the severely damaged maintenance surface, and adjusting the foundation to correct the inclined wall surface. Clean up and repair part of the external walls, try to retain the historical vicissitudes of the old building, and retain the sense of memory. Use organic renewal methods to rejuvenate and reappear charm as it is shown in Fig. 4.

Pollack Periodica 15, 2020, 3 


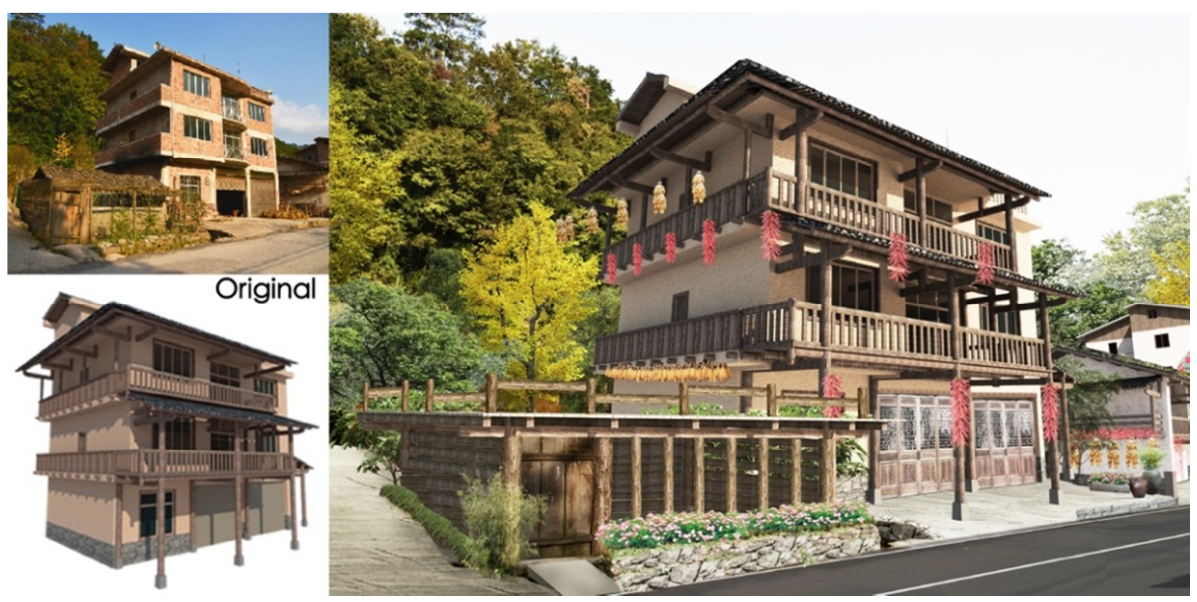

Fig. 3. Adding local architectural components on the facade (Source: designed and drawn by Y. Shi and Y. Shi and Y. Zhao)

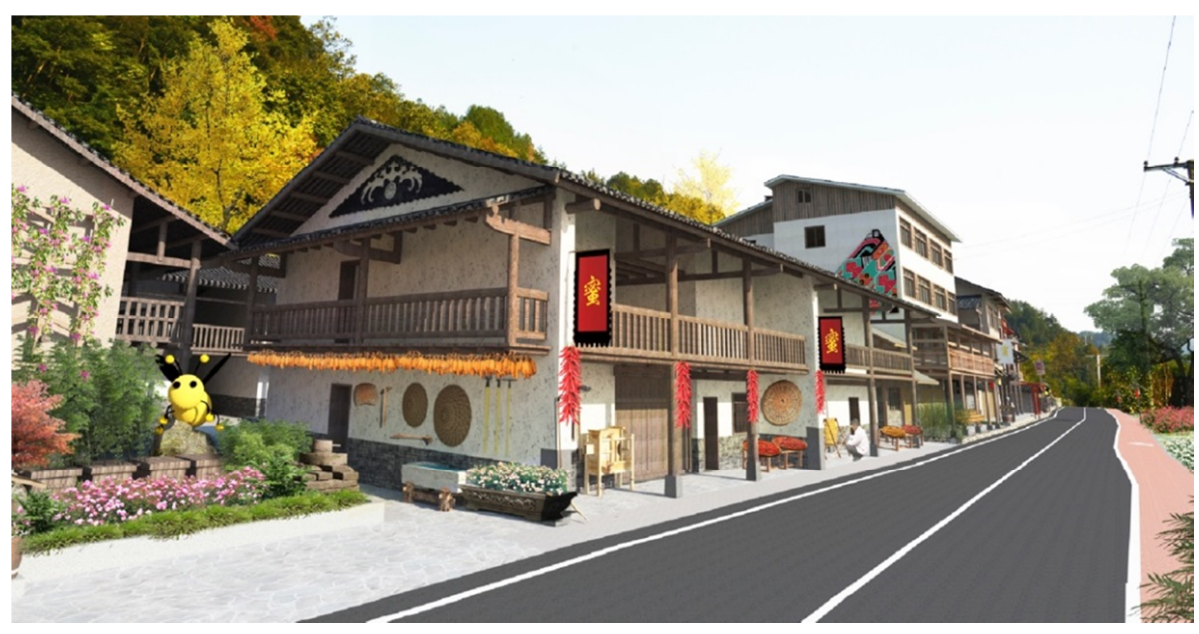

Fig. 4. Low-tech to enhance the regional characteristics of buildings (Source: designed and drawn by Y. Shi and Y. Shi and Y. Zhao)

\subsection{Transform the courtyard and public space with low-tech}

The courtyard is not only a space for villagers to live, but also a place for tourists to experience rural life. The courtyards of the pilot site mostly present a messy scene. In the design, the low-tech in landscape, micro update methods are used to clean up garbage and useless items, and then set up reasonable and useful space. Flower gallery frame and seats are used in the courtyard. The design focuses on giving full play to the initiative of the villagers, creatively using local appliances and idle living objects to create an environment with a sense of life and experience. The design of public space is 
also to design suitable communication space and activity place according to local conditions in the way of low cost and emphasis on creation, to integrate rural life atmosphere into the environment and make it a feature of rural tourism, instead of investing a lot of money and manpower to make large-scale construction as it is shown in Fig. 5 .
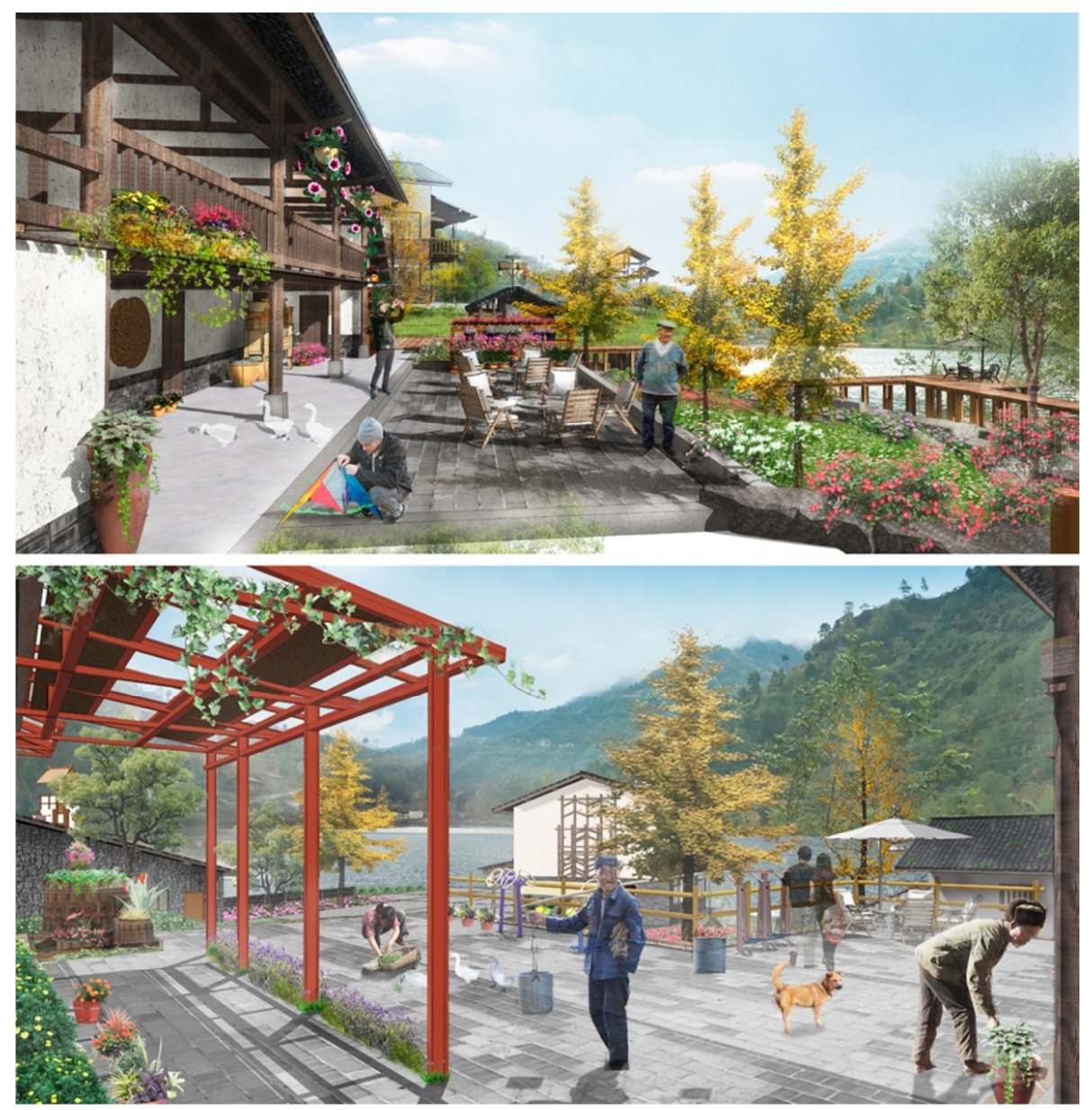

Fig. 5. Transform courtyard and public space by landscape micro upgrade (Source: designed and drawn by Y. Shi and Y. Shi and Y. Zhao)

\subsection{Focus on artistic visualization of tourism cultural symbols}

Culture is the soul of tourism and tourism is the carrier of culture [8]. People usually understand abstract culture through recognizable symbols. In the rural construction with tourism as the main industry, it is a common way to use symbols to express the traditional culture or unique tourism culture. Traditional symbol is an effective and no 
negligible material of creating attractive form [9]. As a symbol carrier, architecture has its responsibility of reveal the truth of its surroundings and the times meanwhile it has to be powerful magnets with distinctive appeal. In combination with the theme of the pilot area's idyllic and sweet environment about bees, bee models are used in the design to enhance the artistry and interest of the rural landscape. Beekeeping implements are also presented as art installations on the framework of the external walls of buildings, which not only continue the local architectural characteristics but also strengthen the tourist cultural symbols.

In addition, a series of signboards with the theme of images related to the bee, honey and beekeeping industry are designed and placed on the roadside and site boundary to enhance environmental identification while continuously spreading local tourism and cultural symbols. The repetition of tourist cultural symbols can not only enhance the local villagers' sense of identity and self-confidence, but also deepen tourists' understanding of the village as it is shown in Fig. 6

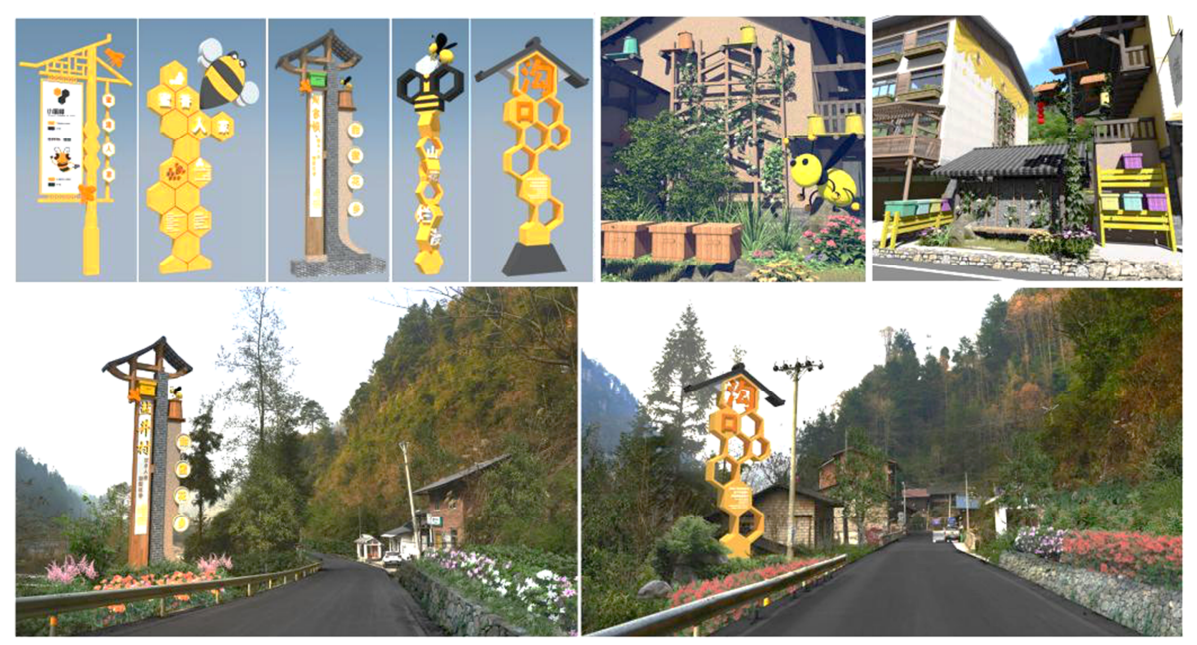

Fig. 6. Visualization of tourist cultural symbols

(Source: designed and drawn by Shi and Y. Shi and Y. Zhao)

\section{Conclusion}

Rural landscape plays an important role in the sustainable development of rural areas in the new era. Villages with regional characteristics and rural idyllic features can usually get the first chance of success in the sustainable development of rural areas supported by tourism as an important industry. In areas where the quality resources of rural cultural landscapes are insufficient or severely damaged, it is particularly important to use multiple methods to restore the ecological environment and reshape contemporary local features with regional characteristics. In the process of restoration and reconstruction, the overall planning and high-tech construction technologies that are commonly used for rapid urban development are not very effective. Instead, local 
technologies with low-tech and low-interference techniques and artistic interventions that enhance environmental aesthetics and emotional resonance can more effectively stimulate rural ecological vitality and self-renewal.

\section{Acknowledgments}

The preparation of this paper was supported by Marcel Breuer Doctoral School, University of Pécs. The whole design process was supported by Professor Yu Zhao of Sichuan Fine Arts Institute, Chongqing, China.

\section{Open Access statement}

This is an open-access article distributed under the terms of the Creative Commons Attribution 4.0 International License (https://creativecommons.org/licenses/by/4.0/), which permits unrestricted use, distribution, and reproduction in any medium, provided the original author and source are credited, a link to the CC License is provided, and changes - if any - are indicated. (SID_1)

\section{References}

[1] ICOMOS-IFLA, Principles concerning rural landscape as heritage (GA 2017 6-3-1 Doctrinal Texts Ver. 30/07/2017), International Council on Monuments and Sites New Delhi, India, 2017.

[2] Hadzic D., Molnar T. Post conflict reconstructions in Bosnia and Herzegovina, Pollack Periodica, Vol. 14, No. 3, 2019, pp. 21-30.

[3] Khalil A. A., Fikry M., Abdeaal W. High technology or low technology for buildings envelopes in residential buildings in Egypt, Alexandria Engineering Journal, No. 57, 2018, pp. 3779-3792.

[4] Cheng J. S., Xiang Y., Sher P. J. Artistic intervention, intellectual capital, and service innovation: a case study of a Taiwan's hotel, Service Business, Vol. 12, No. 1, 2018, pp. 169-201.

[5] Cheng J. S., Liu C. W. Service innovation strategy in the hotel industry: an artistic intervention perspective, Proceedings of the I. International Conference on Tourism Dynamics and Trends, Antalya, Turkey, 4-7 May 2016, pp. 108-117.

[6] Zhou W., Wang J. Research on public art intervention in rural public space transformation, Proceedings of the 4th International Conference on Arts, Design and Contemporary Education, Zhengzhou, China, 6-8 May 2018, Vol. 232, pp. 319-322.

[7] Zhao D., Bachmann B., Wang T. 'Beautiful China' project: a development proposal for non-heritage rural areas in north China, Pollack Periodica, Vol. 14, No. 1, 2019, pp. 235-246.

[8] Wang F., Liao K. Cultural tourism analysis from the perspective of tourism product, Journal of Beijing International Studies University, No. 9, 2012, pp. 9-13.

[9] Zhang Q., Hutter A. From traditional symbol to new contemporary form, Pollack Periodica, Vol. 14, No. 3, 2019, pp. 3-10. 